\title{
COMPUTER SIMULATION OF TRANSPORT AND MAINTENANCE METHODS IN A PYROCHEMICAL REPROCESSING PLANT DESIGN
}

\author{
Shigeaki Yonezawa \\ Japan Nuclear Cycle Development Institute \\ Isao Kakehi \\ Japan Nuclear Cycle Development Institute \\ (former)
}

\author{
Yasukazu Tsusaka \\ Japan Nuclear Cycle Development Institute \\ Yasuo Sasaki \\ MITSUI ENGINEERING \& \\ SHIPBUILDING Co., Ltd.
}

1

INTRODUCTION

As a part of the feasibility study (FS) on commercialized fast reactor cycle systems conducted in Japan since 1999, a conceptual design of pyrochemical reprocessing systems has been studied. In a pyrochemical reprocessing plant introducing batch processing, the material transport is undertaken by the material handling equipment, which transports solid form products from a process to next process. The capacity of the transport system affects the whole plant capacity as well as that of process equipment. The automated transport system will be introduced as the material handling system. Furthermore, all equipments are installed in large hot cells, and the maintenance work is done by using material handling equipment with remote control. In this study, the material handling system was investigated by using virtual engineering.

\section{OUTLINE OF STUDY}

The material handling system for the transport and the remote maintenance in the pyrochemical reprocessing plant was designed. 3D-CAD data of equipment and the operation flow were combined to provide the virtual model. The motion at processing of each equipment, the tarnsport among the equipments with transpoter and the motion of equipment for the work were simulated.

The simulation of the plant operation output Gantt chart. Comparing the net process time with the actual process time, we evaluate the efficiency of transport system. Gantt chart also shows the bottleneck in the process. For the maintenance, the simulation output virtual images and the information of the interference between equipments and units during the work, and we judged the feasibility of maintenance from them.

\section{CONCLUSIONS}

(i) The computer simulation system for the design of the pyrochemical reprocessing plant was developed. It was revealed that the computer simulation was essential to investigate the feasibility of the design in the material handling system.

(ii) The transport system was designed and their contribution to the rational plant operation was revealed.

(iii) The remote maintenance system was designed and feasibility of the remote control material handling was revealed. 